\title{
RESPOSTAS MORFOFISIOLÓGICAS DE PLANTAS DE AÇACU (Hura crepitans L.) PROVENIENTES DE VÁRZEAS DO RIO AMAZONAS: EFEITO DA ANOXIA DO SOLO ${ }^{1}$
}

\author{
Gladys Beatriz Martinez², Moisés Mourão² e Silvio Brienza Junior²
}

\begin{abstract}
RESUMO - Neste trabalho foram avaliadas as respostas morfofisiológicas de plantas de açacu (Hura crepitans) sob a anoxia do solo com diferentes idades (90 e 120 dias) e períodos de inundação (0, 10, 20 e 30 dias). O estudo identificou que as plantas desenvolveram mecanismos adaptativos (estruturas morfológicas como lenticelas hipertróficas e raízes adventícias) e apresentaram comportamento fisiológico que lhes propiciaram tolerância à anoxia. As respostas das plantas ao excesso de água no solo incluíram inibição do crescimento vegetativo, clorose e senescência foliar. O estresse hídrico por anoxia comprometeu a viabilidade das plantas de 90 dias de idade, enquanto as plantas de açacu de 120 dias de idade mostraram-se tolerantes ao alagamento.

Palavras-chave: Várzea amazônica, Anoxia e Espécie florestal.
\end{abstract}

\section{MORPHOPHYSIOLOGICAL RESPONSES OF AÇACU (Hura crepitans L.) PLANTS FROM AMAZON RIVER FLOODPLAINS: ANOXIC SOIL EFFECTS}

\begin{abstract}
It was evaluated in this study the morpho-physiological responses of seedlings of açacu (Hura crepitans) in anoxic soil at different ages (90 and 120 days) and periods of flooding (0,10, 20 and 30 days). The study found that the seedlings developed adaptive mechanisms (morphological structures such as hypertrophic lenticels and adventitious roots) and showed physiological behavior which resulted anoxia tolerance. The responses of plants excess of water in the soil included inhibition of vegetative growth, chlorosis and leaf senescence. Soil water stress affected negatively the viability of seedlings at 90 days of age whereas açacu plants at 120 days of age were tolerant to flooding..
\end{abstract}

Keywords: Amazonian floodplain, Anoxia and Forest species..

\section{INTRODUÇÃO}

O regime de inundação das várzeas do rio Amazonas e afluentes é anual, alternando um período de enchente e outro de vazante. A variação nos regimes de inundação é um importante fator de manutenção da diversidade de espécies em uma comunidade de plantas (POLLOCK et al., 1998; KOZLOWSKI, 1984; VERVUREN et al., 2003).

A inundação do solo provoca diminuição da troca gasosa entre o solo e a atmosfera devido à baixa difusão do oxigênio na água. Além disso, as altas temperaturas que ocorrem na região Amazônica propiciam maior consumo de oxigênio pelas raízes, pela fauna do solo e pelos microrganismos (TAIZ; ZEIGER, 2004), ocasionando o surgimento de gases como nitrogênio, carbônico, hidrogênio e amônia, além de outros compostos que podem surgir e atingir níveis tóxicos às plantas, comprometendo seu desenvolvimento e a germinação das sementes (FERREIRA et al., 2005). Aágua em excesso no solo também pode provocar modificações em sua forma e estrutura (BENINCASA, 1986). A concentração interna de $\mathrm{O}_{2}$ em plantas aclimatadas ou não decresce drasticamente sob a condição de anoxia somente se a água estiver estagnada (LENSSEN et al., 2004). As plantas que se desenvolvem em solos sujeitos a alagamento se beneficiam da ação de mecanismos adaptativos envolvendo estruturas que propiciam a tolerância das plantas a esses ambientes. As respostas

\footnotetext{
${ }^{1}$ Recebido em 18.11.2009 e aceito para publicação em 31.10.2011.

2Empresa Brasileira de Pesquisa Agropecuária, Embrapa, Brasil. E-mail: <gladys@cpatu.embrapa.br>.
} 
à inundação podem variar intensamente de acordo com as espécies, a sua constituição genética e a duração da inundação (ROGGE et al., 1998). O desenvolvimento de plantas arbóreas é afetado adversamente pela inundação do solo em poucas semanas, principalmente na fase de desenvolvimento (KOZLOWSKI, 1984).

A riqueza e diversidade de espécies e o estoque de biomassa da floresta de várzea são menores que na floresta de terra firme devido às limitações de adaptação da vegetação ao regime de inundação (GAMA et al., 2005). Os períodos de inundação em que a lâmina d'água cobre o solo por períodos e níveis maiores podem levar à morte as plântulas, produzindo diferenças na sua estrutura e densidade (SOARES; OLIVEIRA, 2009). Além disso, a distribuição das espécies nos ecossistemas em geral é determinada, entre outros fatores, pela sucessão de ocorrência dos eventos naturais causadores de distúrbios (VERVUREN et al., 2003), como a inundação em áreas ribeirinhas.

Um grande número de espécies vegetais se desenvolve nas várzeas do Baixo Amazonas, e muitas delas são utilizadas diretamente para o consumo da população local ou têm função ecológica, tornando-se importantes componentes desse ecossistema. Entre as espécies, encontra-se o açacu (Hura crepitans L.), Euphorbiaceae arbórea de grande porte e que se destaca como uma das mais frequentes espécies da floresta de várzea do Estado do Pará (GAMA et al., 2005). Sua madeira é usada em obras internas, artesanatos, utensílios de madeira (caixotes e tamancos), e suas propriedades medicinais concentram-se em inseticida e vomicida.

Na literatura não foram encontrados estudos sobre o comportamento dessa espécie em condição de estresse hídrico. Entretanto, o conhecimento empírico indica sua capacidade de sobrevivência em ambientes inundados (MARTÍNEZ, 2008), fato que permite pressupor que ocorram alterações morfofisiológicas que amenizam os efeitos da redução de $\mathrm{O}_{2}$ no solo. $\mathrm{O}$ entendimento sobre como ocorrem os danos às plantas e os mecanismos de adaptação à deficiência de oxigênio possui importâncias ecológica, econômica (VARTAPETIAN; JACKSON, 1997) e social. Nesse sentido, o objetivo deste trabalho foi avaliar as respostas morfofisiológicas de plantas de açacu com diferentes idades e submetidas a quatro períodos de inundação.

\section{MATERIAL E MÉTODOS}

As sementes de açacu (Hura crepitans L.) foram coletadas em áreas de várzea banhadas pelo rio Amazonas e afluentes, na microrregião de confluência dos municípios de Santarém, Prainha e Monte Alegre (Baixo Amazonas, Estado do Pará). Após 15 dias de sua coleta, as sementes foram semeadas em vasos plásticos em casa de vegetação da Embrapa Amazônia Oriental, em Belém, Pará.

Foram utilizadas 72 plantas, distribuídas em oito tratamentos, sendo duas idades (90 e 120 dias) e quatro períodos de alagamento $(0,10,20$ e 30 dias). Os tratamentos foram distribuídos em três repetições, e cada unidade amostral foi composta de três plantas. A lâmina de água para a inundação foi de aproximadamente $4 \mathrm{~cm}$, sendo seu nível mantido diariamente para compensar as perdas por evapotranspiração. As plantas não inundadas foram irrigadas diariamente. A drenagem dos vasos foi realizada mediante uma perfuração em seu fundo, bloqueada por saco de plástico durante o período de inundação. Após a drenagem, as plantas foram mantidas no local e irrigadas, quando necessário, até o término do experimento, que ocorreu 60 dias após sua implantação.

A cada 10 dias foram coletados dados dos indicadores de crescimento das plantas em altura (do coleto até a parte mais alta da planta), diâmetro do coleto (a $5 \mathrm{~cm}$ do solo) e número de folhas, comprimento e largura de duas folhas/plantas que determinaram sua área foliar, ajustada por um fator de correção. Esse fator de correção foi obtido pela relação direta entre uma área e peso conhecidos (papel) e o peso de recortes, do mesmo material, de diversas folhas. No final do experimento, as plantas foram cortadas para cálculo da biomassa seca (total e frações da folha, caule e raiz). As alterações morfológicas, clorose, senescência foliar, formação de lenticelas hipertróficas, raízes adventícias na base do caule e abscisão foliar, observadas visualmente nas plantas inundadas, foram anotadas diariamente a partir do décimo dia após a inundação do solo.

A influência do alagamento sobre os indicadores de crescimento das plantas (altura, diâmetro do coleto, área foliar, número de folhas e folíolos e folíolos por folha) foi verificada por meio de análise de variância com medidas repetidas. A significância dos efeitos na ordenação univariada dos valores médios foi obtida por meio do teste de Duncan. Tanto para a análise de

Revista Árvore, Viçosa-MG, v.35, n.6, p.1155-1164, 2011

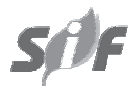


variância quanto para o teste de comparação múltipla foi adotado o nível de significância de $5 \%(\alpha=0,05)$. Ressalta-se que, no caso do modelo de análise de variância com medidas repetidas no tempo, foram adotadas as correções de graus de liberdade de Greenhouse-Geisser (G-G) e Huynh-Feldt (H-F) (GLM SAS).

Os valores finais das avaliações de crescimento foram ordenados por meio da técnica multivariada de análise de fatores (factor analysis), utilizando os componentes principais como métodos de extração. A regra de Kaiser foi adotada para determinação dos autovalores e de um limiar de $|\lambda| \geq 0,50$ para os autovetores (MANLY, 1994; JOHNSON; WICHERN, 1998). Os escores obtidos na análise de fatores de cada um dos componentes foram testados por meio de uma análise de variância sob a estrutura fatorial, sendo as estruturas dos níveis conjugados de idade das plantas e tempo de alagamento evidenciados, graficamente, por meio da técnica de envoltório convexo (convex hull).

Para classificar as plantas em função do seu grau de desenvolvimento e condição de anoxia, foi feita uma análise de agrupamento (cluster analysis), utilizando-se todos os indicadores de crescimento, com o objetivo de polarizar as variáveis em grupos de maior discriminância. Para a ordenação dos tratamentos, aplicou-se uma Análise de Componentes Principais, identificando as variáveis mais importantes no espaço de cada componente principal (CPA).

A fitomassa acumulada ao final do experimento, bem como seu fracionamento e o seu incremento ao longo do experimento, foi testada por meio de análise de variância sob a estrutura fatorial. Os valores médios dos níveis de cada efeito foram testados por meio do teste de comparação múltipla de Duncan. Tanto para o modelo de análise de variância quanto para o teste de comparação múltipla, foi adotado o nível de significância de 5\% $(\alpha=0,05)$.

As análises foram conduzidas com o auxílio da planilha eletrônica Excel e dos pacotes estatísticos SAS System ® e STATISTICA 5.5 (C) (SAS, 1990; STATSOFT, 2001).

\section{RESULTADOS}

Os resultados referem-se a parâmetros morfofisiológicos que, no conjunto, caracterizam o aspecto comportamental da espécie quando submetida à inundação temporária do solo, permitindo avaliar sua tolerância a esse tipo de estresse.
Todas as plantas de açacu estudadas sobreviveram à inundação do solo. A partir da primeira observação visual, décimo dia de alagamento do solo, constatou-se o aparecimento de clorose, senescência foliar e formação de lenticelas hipertróficas, raízes adventícias na base do caule, deslocamento das raízes para a superfície da lâmina d'água (Figura 1) e abscisão das folhas mais velhas. O desenvolvimento de lenticelas hipertróficas e raízes adventícias foi observado, respectivamente, em $17,33 \%$ e $17 \%$ das plantas com 90 dias de idade e em 67,83\% e 33-67\% das plantas com 120 dias. Essas variações ocorreram em função do tempo de inundação, e as estruturas regrediram após a drenagem do solo.

A análise de altura das plantas (Figura 1a) apontou diminuição na taxa de crescimento diário (Incremento Médio de Altura-IMA) para os indivíduos sob alagamento com 90 dias de idade a partir do décimo dia de inundação (IMA = 0,2-0,4 $\mathrm{cm} \mathrm{dia}^{-1}$ ), quando comparado com as plantas sem alagamento (IMA $=0,7 \mathrm{~cm} \mathrm{dia}^{-1}$ ). Para essa idade, aproximadamente 10 dias após a drenagem da água o crescimento de todas as plantas alagadas normalizou-se ( IMA = 0,4-0,6 cm dia-1). A inundação alterou o desenvolvimento em altura das plantas de açacu com idade de 120 dias (IMA = 1,35 $\mathrm{cm} \mathrm{dia}^{-1}$ ), em comparação com as plantas não alagadas (IMA $=1,42 \mathrm{~cm} \mathrm{dia}^{-1}$ ). Entretanto, não houve alteração relativa ao tempo de inundação.

O diâmetro do coleto não sofreu interferência do alagamento, entretanto diferenças significativas relacionadas à idade das plantas foram detectadas. Ao final do experimento, as plantas apresentaram incremento médio do diâmetro do coleto (IMC) entre 0,013 e $0,015 \mathrm{~cm}$ em plantas de 90 dias de idade e de 0,020 e 0,022 cm nas de 120 dias (Figura 1b).

O alagamento do solo propiciou a redução no saldo do número de folhas em todos os indivíduos a partir do $10^{\circ}$ dia de inundação. O efeito mais severo desse parâmetro foi detectado 10 dias após cessada a inundação. Nesse período, as plantas inundadas de 90 dias sofreram redução no número de folhas entre 31 e $76 \%$, comparadas às plantas não inundadas, e as de 120 dias de idade, entre 6 e 43\%. Essa variação ocorreu de acordo com o tempo de inundação, e as plantas que permaneceram por mais tempo inundadas (30 dias) sofreram maior impacto (Figura 1c). A senescência seguida de abscisão foliar ocasionada pela inundação nas plantas com 90 
(a)

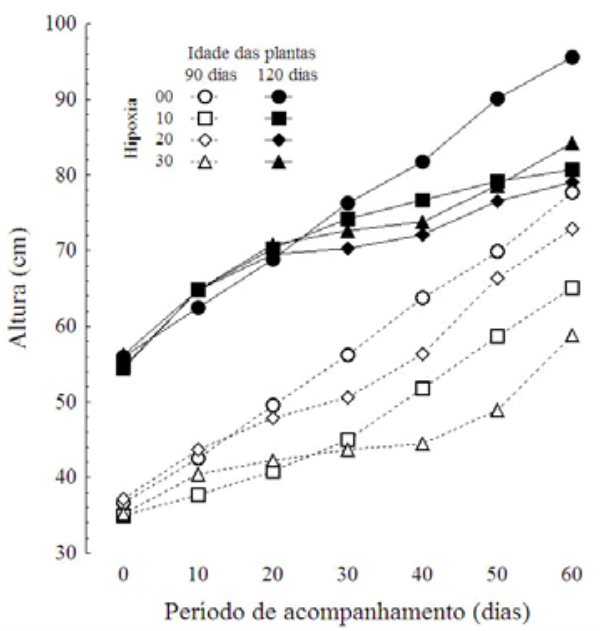

(c)

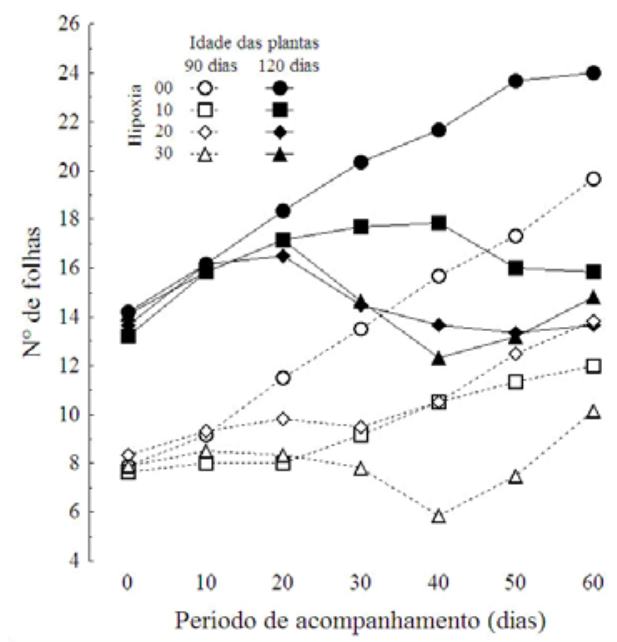

(b)

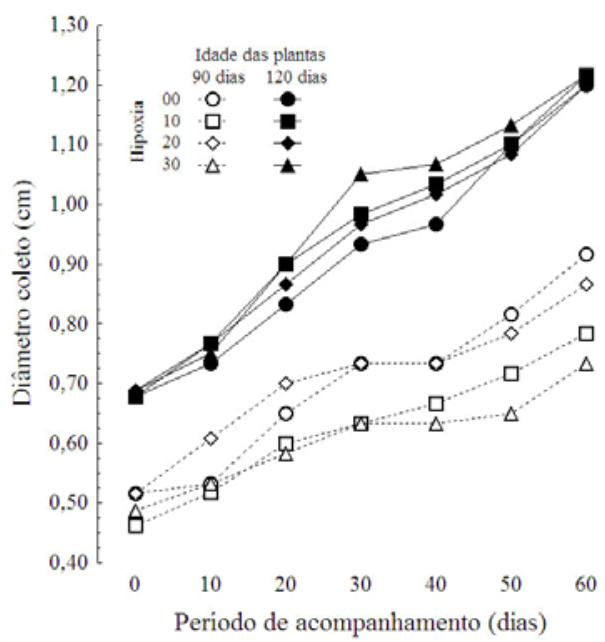

(d)

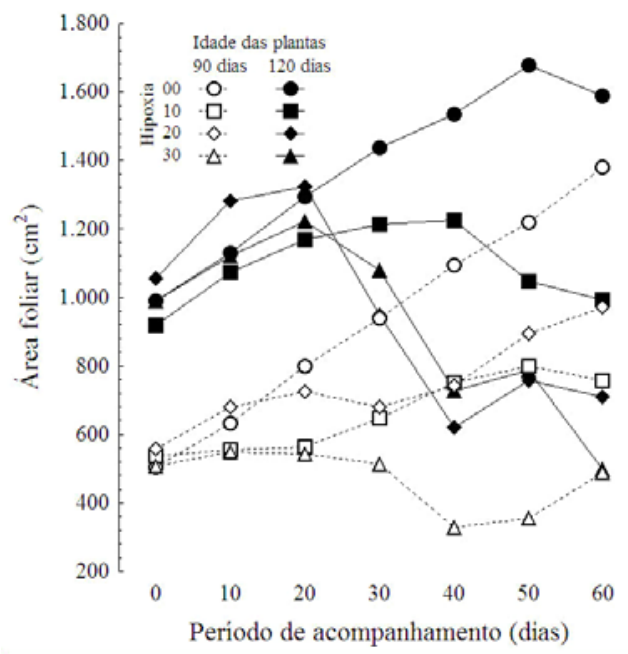

Figura 1 - Valores médios de (a) altura, (b) diâmetro do coleto, (c) número de folhas e (d) área foliar de plantas de açacu com duas idades, em função de quatro períodos de anoxia do solo.

Figure 1 - Mean values of (a) height, (b) diameter, (c) number of leaves and (d) leaf area of açacu plants at two ages in four different periods of soil anoxia.

dias de idade e submetidas a 30 dias de alagamento chegou a $50 \%$ no final do estudo (sem alagamento: 20 folhas; sob alagamento: 10 folhas) e cerca de $40 \%$ nas plantas de 120 dias de idade (sem alagamento: 24 folhas; sob alagamento: 14-16 folhas).

A redução da área foliar foi detectada a partir do $20^{\circ}$ dia de inundação nas plantas de 90 dias de idade. As plantas sem alagamento apresentaram área foliar de $798 \mathrm{~cm}^{2}$ e sob alagamento, de 542 a $726 \mathrm{~cm}^{2}$, correspondendo a uma redução de 9 a 32\%, de acordo com o tempo de inundação. Entretanto, 10 dias após a drenagem do solo a área foliar foi restabelecida aos níveis das plantas sem inundação. Nas plantas de 120 dias de idade, a redução da área foliar foi gradativa e ocorreu somente a partir do $30^{\circ}$ dia após a inundação. Nesse período, as plantas sem alagamento apresentaram área foliar de $1.436 \mathrm{~cm}^{2}$ e sob alagamento, entre 947 e $1.213 \mathrm{~cm}^{2}$, correspondendo a uma redução de 16 a $34 \%$, de acordo com o tempo de inundação. Ao final do experimento, as plantas de 120 dias de idade, sem

Revista Árvore, Viçosa-MG, v.35, n.6, p.1155-1164, 2011 
alagamento, apresentaram área foliar de $1.589 \mathrm{~cm}^{2}$ e sob alagamento, entre 498 e $991 \mathrm{~cm}^{2}$, correspondendo a uma diminuição de 38-69\% (Figura 1d).

A análise de agrupamento (cluster analysis) identificou três agrupamentos das plantas estudadas, sendo: (i) plantas sem alagamento, (ii) plantas de 120 dias de idade sob alagamento; e (iii) plantas de 90 dias de idade sob alagamento (Figura 2a). A partir do estabelecimento dos agrupamentos, evidenciados na análise de agrupamento, foi possível determinar os valores médios dos indicadores de crescimento das espécies estudadas (Tabela 1). Pela análise fatorial (factor analysis) foram extraídos dois componentes principais, os quais captaram cerca de $89 \%$ da variação global. O CPA-I apresentou as variáveis altura e número de folhas, com significância $(|\lambda|>0,50)$, e ambas com orientação positiva, representando cerca de $68 \%$ da variação global. O CPA-II mostrou, com significância ( $|\lambda|>0,50)$, as variáveis diâmetro do coleto, com orientação negativa e área foliar das plantas, com orientação positiva, abrangendo cerca de $21 \%$ da variação global (Figura 2b). A partir desses escores foi possível evidenciar a seguinte ocorrência nas plantas de açacu: (i) redução tanto do componente de porte da planta (altura e diâmetro do coleto) quanto dos componentes de atividade fotossintética (número de folhas e área foliar da planta), nas plantas com 90 dias de idade sob alagamento; (ii) manutenção exclusiva do componente porte da planta e também redução nos componentes da atividade fotossintética, nas plantas com 120 dias de idade e sob alagamento; e (iii) manutenção do componente porte da planta e incremento do componente atividade fotossintética, nas plantas sem alagamento.

Tabela 1 - Valores médios dos indicadores de crescimento das plantas de açacu a partir do estabelecimento dos agrupamentos evidenciados na análise de agrupamento.

Table 1 - Mean values of indicators of açacu plant growth from the establishment of groups formed by cluster analysis.

\begin{tabular}{|c|c|c|c|}
\hline \multirow[t]{2}{*}{ Condição de alagamento } & \multirow[t]{2}{*}{ Ausência de alagamento } & \multicolumn{2}{|c|}{ Alagado - Idade das plantas } \\
\hline & & 90 dias & 120 dias \\
\hline$\overline{\text { Altura }}$ & $85,36 \mathrm{~cm}$ & $65,61 \mathrm{~cm}$ & $81,31 \mathrm{~cm}$ \\
\hline Diâmetro do coleto & $1,05 \mathrm{~cm}$ & $0,79 \mathrm{~cm}$ & $1,21 \mathrm{~cm}$ \\
\hline Número de folhas & 22,27 & 12,00 & 14,78 \\
\hline Área foliar da planta & $1.569,65 \mathrm{~cm}^{2}$ & $736,44 \mathrm{~cm}^{2}$ & $750,08 \mathrm{~cm}^{2}$ \\
\hline
\end{tabular}

A)

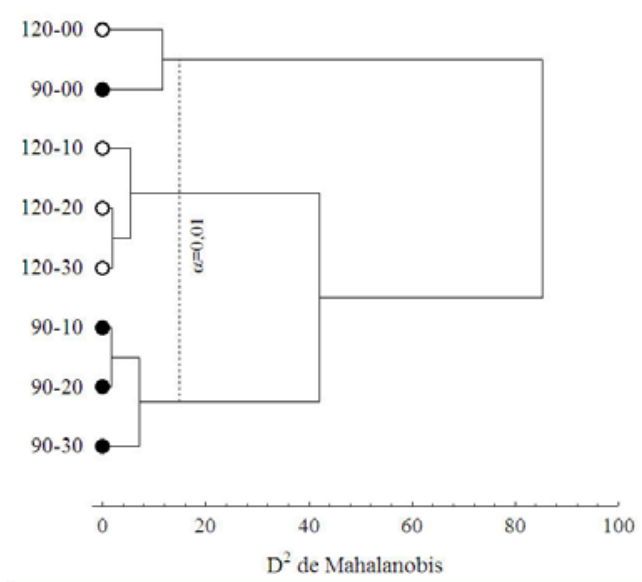

B)

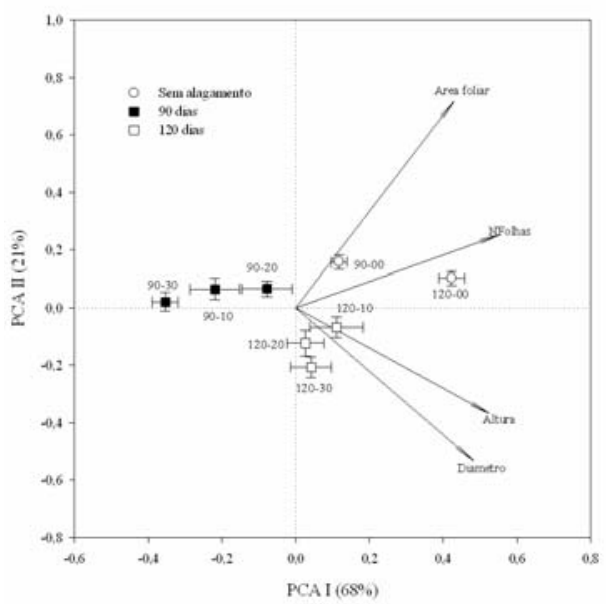

Figura 2 - (a) Dendrograma de dissimilaridade entre as diferentes condições de grau de desenvolvimento do açacu sob anoxia e (b) disposição dos escores médios e erro-padrão obtidos na análise de componentes principais dos indicadores de crescimento de açacu ao final do estudo.

Figure 2 - (a) Dendrogram of dissimilarities between the different conditions of physiological maturity of açacu under anoxia and (b) provision of mean scores and standard error obtained in principal component analysis of açacu growth indicators at the end of the study. 
Tabela 2 - Valores médios ordenados, segundo o teste de Tukey $(\alpha=0,05)$, de frações de fitomassa (\%) das plantas de açacu ao longo do experimento.

Table 2 - Mean values, ordered according to the Tukey test ( $\alpha=0.05)$, fractions of açacu plants biomass (\%)throughout the experiment.

\begin{tabular}{cccccccc}
\hline \multirow{2}{*}{$\begin{array}{c}\text { Idade das } \\
\text { (dias) }\end{array}$} & $\begin{array}{c}\text { Alagamento } \\
\text { (dias) }\end{array}$ & \multicolumn{5}{c}{ Açacu } \\
\cline { 3 - 8 } & 0 & 17,9 & $\mathrm{a}^{1}$ & 53,9 & $\mathrm{a}^{1}$ & 28,2 & $\mathrm{~b}^{1}$ \\
\hline 90 & 10 & 15,5 & $\mathrm{a}^{1}$ & 50,6 & $\mathrm{a}^{1}$ & 34,0 & $\mathrm{ab}^{1}$ \\
& 20 & 13,9 & $\mathrm{a}^{1}$ & 48,4 & $\mathrm{a}^{1}$ & 37,7 & $\mathrm{a}^{1}$ \\
& 30 & 16,2 & $\mathrm{a}^{1}$ & 48,5 & $\mathrm{a}^{1}$ & 35,3 & $\mathrm{ab}^{1}$ \\
120 & 0 & 20,6 & $\mathrm{a}^{1}$ & 51,2 & $\mathrm{a}^{1}$ & 28,2 & $\mathrm{~b}^{1}$ \\
& 10 & 16,9 & $\mathrm{ab}^{1}$ & 48,2 & $\mathrm{a}^{1}$ & 34,8 & $\mathrm{ab}^{1}$ \\
& 20 & 15,8 & $\mathrm{ab}^{1}$ & 47,7 & $\mathrm{a}^{1}$ & 36,5 & $\mathrm{a}^{1}$ \\
& 30 & 14,5 & $\mathrm{~b}^{1}$ & 51,5 & $\mathrm{a}^{1}$ & 34,1 & $\mathrm{bb}^{1}$ \\
\hline
\end{tabular}

Em que: P.A.= período de acompanhamento; letras latinas, na horizontal $=$ efeito do tempo de inundação, em cada uma das idades de plantas; e algarismos arábicos, na horizontal = efeito da idade das plantas, em cada um dos tempos de inundação. Valores precedidos de mesma letra ou algarismo não diferem significativamente, segundo o teste de Tukey a 5\%.

Where: PA - follow-up period, Latin letters in the row-effect of time of flooding, in each of the ages of plants, Arabic numerals in the horizontal - effect of age of plants in each of the times of flooding. Values preceded by the same letter or number, do not differ significantly according to Tukey test at $5 \%$.

A fração de biomassa de folhas das plantas de açacu (14,5\% da fitomassa total) com 120 dias de idade, em condições de estresse hídrico mais severo (30 dias sob alagamento do solo), foi menor quando comparada com a ausência de alagamento (20,6\%). Nas plantas de 90 dias de idade, a fração de biomassa de folhas apresentou valores entre 13,9 e 17,9\% da fitomassa total, representando um padrão de alocação equivalente nos diferentes tempos de inundação. Equivalência essa também encontrada nas frações de fitomassa alocada para o caule de açacu, tanto nas plantas de 120 dias (médias de 47,7 a 51,5\%) quanto nas de 90 dias de idade (48,4 a 53,9\%).

A inundação provocou aumento da fração de fitomassa de raízes das plantas de açacu nas duas idades de maturação fisiológica estudadas. A fração média de raiz na ausência de alagamento foi de 28,2\% da fitomassa total das plantas, independentemente da idade; sob alagamento, variou de 34,0 a 37,7\% (plantas de 90 dias de idade) a 34,1 a 36,5\% (plantas de 120 dias). Apesar do aumento na alocação de fitomassa nas raízes das plantas inundadas, o volume radicular das plantas de açacu de 90 dias de idade reduziu na ordem de 24

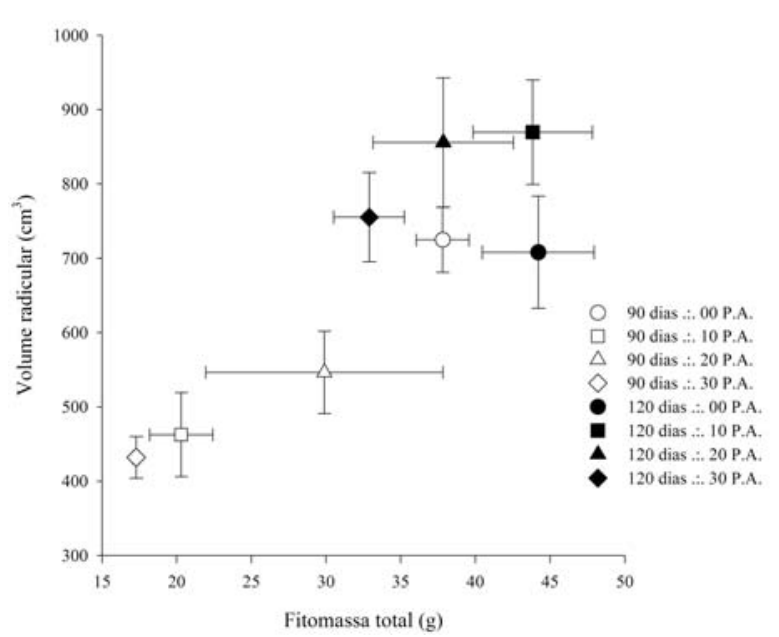

Figura 3 - Valores médios e erro-padrão da média de fitomassa total e volume radicular de açacu, em função dos tratamentos avaliados.

Figure 3 - Mean values and standard error of the average total biomass and root volume of Açacu, in function of the evaluated treatments.

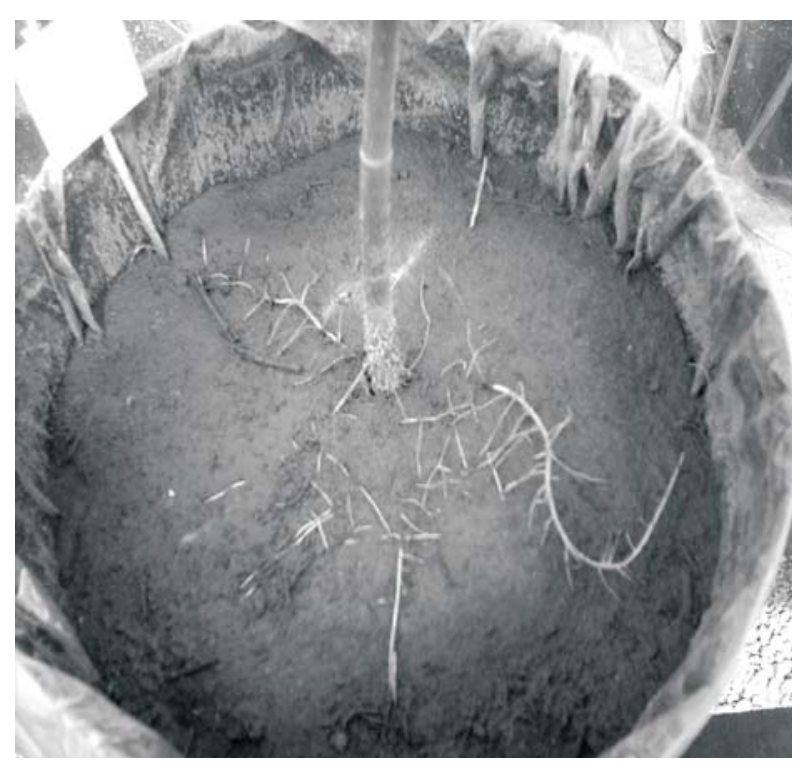

Figura 4 - Algumas alterações morfofisiológicas - raízes adventícias, lenticelas hipertróficas e deslocamento de raízes para a superfície da água - apresentadas pelas plantas de açacu inundadas.

Figure 4-Some morphophysiological changes - adventitious roots, hypertrophic lenticels and displacement of roots to the water surface-presented by flooded açacu plants. 
a 40\% (sem alagamento: $724,66 \mathrm{~cm}^{3}$; e sob alagamento de 432,01 a $546,28 \mathrm{~cm}^{3}$ ), mantendo-se inalterado nas plantas de 120 dias de idade.

A inundação também reduziu a fitomassa total na ordem de 20 a 54\% nas plantas de açacu de 90 dias de idade ao final do experimento (sem alagamento: 37,81 g; e sob alagamento, entre 17,89 e 29,88 g). Entretanto, no caso das plantas de 120 dias, observou-se equivalência entre as condições de presença e ausência de alagamento, seja com relação à fitomassa total (5,91 a 43,46 g), seja com relação ao volume radicular (728,14 a $\left.866,08 \mathrm{~cm}^{3}\right)$.

\section{DISCUSSÃO}

A tolerância das espécies ao alagamento é baseada na capacidade de crescimento e sobrevivência das plantas, as quais utilizam estratégias para sobrepor as injúrias dos ambientes inundados. A mortalidade de plantas submetidas à inundação varia grandemente de acordo com a duração da inundação e com a espécie e idade das plantas (KOSLOWSKI, 1984). A espécie estudada neste trabalho mostrou adaptar-se às condições anóxicas, principalmente em termos da sobrevivência de todos os indivíduos estudados. A observação do desenvolvimento de lenticelas hipertróficas e raízes adventícias, estimuladas pelo alagamento do solo, sugere que essas estruturas contribuíram para que as plantas suportassem, pelo menos, 30 dias em ambiente anóxico. Plantas de Schizolobium parahyba submetidas à inundação somente retomaram o crescimento normal após a emissão de raízes adventícias (COSTA et al., 2006). Diversos estudos reportaram o fechamento dos estômatos em resposta à inundação como forma de proteção contra o déficit hídrico da planta (SMIT et al., 1989; LOPEZ; KURSAS, 1999; GONG et al., 2007), porém a reabertura poderá ocorrer quando as primeiras raízes adventícias aparecerem na planta (SENA GOMES e KOZLOWSKI, 1980). Os resultados deste trabalho indicaram que as raízes adventícias podem incrementar a capacidade de absorção de água e compensar a perda da capacidade de absorção do sistema radicular original (YAMAMOTO et al., 1975; GONG et al., 2007).

Muitas espécies tolerantes à inundação buscam acesso ao oxigênio pelo redirecionamento de suas raízes para a superfície da água ou pela formação de estruturas de suprimento de $\mathrm{O}_{2}$ (SENA GOMES; KOZLOWSKI, 1980; LOPEZ; KURSAR, 1999; COSTA et al., 2006), e não necessariamente pela alta resistência das células das raízes à inundação ou a alguma particularidade do seu metabolismo radicular (VARTAPETIAN; JACKSON, 1997).

A redução no desenvolvimento de plantas submetidas à inundação tem sido frequentemente constatada em diversas espécies vegetais (ROGGE et al., 1998; ANDRADE et al., 1999; MIELKE et al., 2003; POVH et al., 2005; COSTA et al., 2006; MEDRI et al., 2007), sendo a queda no consumo de oxigênio a corresponsável pelo menor crescimento das plantas sob essa condição (KOLB et al., 1998). Tal fato permite inferir que plantas de açacu se adaptam à anoxia do solo, reduzindo seu metabolismo durante o estresse, mecanismo utilizado por Lonchocarpus muehlbergianus e Sesbania virgata, espécies consideradas por Rogge et al. (1998) como tolerantes à inundação.

A redução dos componentes da atividade fotossintética pela condição de anoxia, identificada pela análise de componentes principais e representada pela diminuição do número de folhas e área foliar das plantas, ocorreu em todas as plantas de açacu de 90 dias de idade, uma vez que nas de plantas com 120 dias houve manutenção do desenvolvimento. Esse resultado pode ser explicado pelo fato de a inundação do solo vir geralmente seguida do decréscimo da taxa fotossintética, como consequência do fechamento dos estômatos (KOZLOWSKI, 1997; MIELKE et al., 2003; FARMER; PEZESHKI, 2004).

A inundação reduz a emissão de novas folhas e a expansão foliar, propiciando a diminuição da área foliar das plantas (KOZLOWSKI, 1984), que juntamente com o fechamento dos estômatos pode contribuir para a redução da absorção de carbono, produção de assimilados (LEVITT, 1972) e, consequentemente, de biomassa vegetal de plantas inundadas (MIELKE et al., 2003). Benincasa (1984) acrescentou ainda que a redução da área foliar se dá também pela morte de folhas, pressupondo que a desfolha seja causada pela deficiência de citocinina produzida pelas raízes ou, ainda, pela concentração de gases tóxicos no solo ao redor das raízes. A redução da área foliar de plantas decorrente da inundação também foi observada em Ricinus communis L. (25\%) (BELTRÃO et al., 2003) e em Virola surinamensis (44\%) (LOPEZ; KURSAR, 1999).

A desfolha é uma ocorrência comum e posterior a outros sintomas de injúria decorrentes da anoxia, como clorose e senescência foliar. A redução foliar

Revista Árvore, Viçosa-MG, v.35, n.6, p.1155-1164, 2011 
apresentada pelas plantas de açacu, ao final do estudo, independentemente da idade das plantas, foi superior aos 29,6\% encontrados em Genipa americana no final de 63 dias sob anoxia (MIELKE et al., 2003) e aos 36\% em Himatanthus sucuuba (FERREIRA et al., 2005). Os resultados deste estudo mostraram que a tolerância das plantas à inundação depende, entre outros fatores, da espécie e de sua idade, e as plantas mais velhas toleram mais a inundação que as mais jovens (KOZLOWSKI, 1984).

As plantas possuem estratégias de sobrevivência em ambientes anóxicos. Alterações morfológicas propiciam uma dinâmica de massa, específica para cada espécie e condições ambientais, que culminam na alocação de fitomassa nas diferentes partes da planta. A massa seca é importante parâmetro para avaliar a capacidade das espécies em tolerar a inundação. A fitomassa total das plantas de açacu de 90 dias de idade, ao final do experimento, diminuiu com a inundação. Os resultados permitem inferir que a redução da área foliar, a desfolha e a baixa produção de folhas novas contribuíram para tal fato. A diminuição da fitomassa total é considerada uma resposta típica das plantas à inundação (SENA GOMES; KOZLOWSKI, 1980; KOZLOWSKI, 1984; YAMAMOTO et al., 1975), como o ocorrido com as seguintes espécies submetidas à inundação: Lithraea molleoides (redução de 50\%), Genipa americana (redução de até 35,6\%) e Himatanthus sucuuba (redução de 58\%) (MEDRI et al., 2007).

O padrão de alocação de biomassa de plantas mostra a estratégia de crescimento da espécie. Entretanto, neste estudo a inundação não afetou a alocação de biomassa para o caule semelhante ao ocorrido com plantas inundadas de Fraxinus mandshurica (YAMAMOTO et al., 1975) e Genipa americana (MIELKE et al., 2003). É provável que o curto período de alagamento usado neste estudo não tenha sido suficiente para provocar possíveis alterações na estrutura do caule dessas espécies. Nas plantas de 120 dias, foi registrada redução da fração folha em detrimento de maior alocação de biomassa para as raízes. O aumento na alocação da massa seca de raízes, induzido pela inundação, aconteceu também nas plantas de 90 dias de idade. O incremento na produção de fitomassa nas raízes, encontrado nas plantas inundadas de açacu, pode ser atribuído à formação de raízes adventícias e, ou, à regeneração de novas raízes no sistema radicular original (KOZLOWSKI, 1984), bem como ao crescimento de raízes em direção à superfície da água para captação de $\mathrm{O}_{2}$ da superfície. As espécies Cytharexyllum myrianthum (ANDRADE et al., 1999), Glycine max (PIRES et al., 2002) e Rumex palustris (JANSEN et al., 2005) também apresentaram o mesmo comportamento de alocação de biomassa de raízes quando em solos inundados.

\section{CONCLUSÕES}

O alagamento implicou redução da atividade fotossintética inferida a partir do número de folhas e da área foliar nos graus de desenvolvimento avaliados.

O aumento considerável da fração fitomassa das raízes, mediante o alagamento do solo, pode ter sido determinante para a sobrevivência de todas as plantas estudadas.

Mesmo sob alagamento, as plantas de 120 dias de idade mantiveram o crescimento mirístico equivalente à condição de ausência de alagamento.

Em áreas sujeitas à inundação, recomenda-se o uso de plantas de açacu com idade mínima de 120 dias.

\section{REFERÊNCIAS}

ANDRADE, A. C. S. et al. Flooding effects in seedlings of Cytharexyllum myrianthum Cham. and Genipa americana L.: responses of two neotropical lowland tree species. Revista Brasileira de Botânica, v.22, n.2, p.281-285, 1999. (Suplemento)

BELTRÃO, N. E. M. et al. Fisiologia da mamoneira, cultivar BRS 149 nordestina, na fase inicial de crescimento, submetida a estresse hídrico. Revista Brasileira Oleaginosas e Fibrosas, v.7, n.1, p.659-664, 2003.

BENINCASA, M. M. P. Fisiologia de culturas adaptadas a condições de várzea. In: SIMPÓSIO NACIONAL SOBRE O APROVEITAMENTO DE VÁRZEAS, 1984, Jaboticabal. Anais... Jaboticabal: FUNEP, 1986. p.131-139.

COSTA, A. M. et al. O efeito da inundação do solo sobre o crescimento inicial de Schizolobium parahyba (Vell.) S.F. Blake, guapuruvu.

Natureza On Line, v.4, n.1, p.7-13, 2006. Disponível em: http://www.naturezaonline.com.br. Acesso em: 12 mar. de 2008. 
FARMER, J. W.; PEZESHKI, S. R. Effects of periodic flooding and root pruning on Quercus nuttallii seedlings. Wetlands Ecology and Management, v.12, n.3, p.205-214, 2004.

FERREIRA, C. et al. Tolerância de Himatanthus sucuuba Wood. (Apocynaceae) ao alagamento na Amazônia Central. Acta Botânica Brasílica, v.19, n.3, p.425-429, 2005.

GAMA, J. R. V. et al. Comparação entre florestas de várzea e de terra firme do Estado do Pará. Revista Árvore, v.29, n.4, p.607-616, 2005.

GONG, J. et al. The effects of flooding on several hybrid poplar clones in Northern China.

Agroforest System, v.69, n.1, p.77-88, 2007.

JANSEN, C.; van STEEG, H. M.; KROON, H. Investigating a trade-off in root morphological responses to a heterogeneous nutrient supply and to flooding. Functional Ecology, v.19., n.6, p.952-960, 2005. Disponível em: http://www.ingentaconnect.com. Acesso em: 23 jan. 2008.

JOHNSON, R. A.; WICHERN, D. W. Applied multivariate statistical analysis. 4.ed. New Jersey, Prentice Hall, 1998. 815p.

KOLB, R. M. et al. Anatomia ecológica de Sebastiania commersoniana (Baillon) Smith \& Downs (Euphorbiaceae) submetida ao alagamento. Revista Brasileira de Botânica, v.21, n.3, p. 261-267, 1998.

KOZLOWSKI, T. T. Responses of wood plants to flooding. In: KOZLOWSKI, T. T. Flooding and plant growth. San Diego: Academic Press, 1984. p.129-163.

KOZLOWSKI, T. T. Responses of woody plants to flooding and salinity. Victoria: Heron Publishing, Tree Physiology Monograph, n. 1. p.1-29, 1997. Disponível em: http:// heronpublishing.com/tp/monograph/kozlowski.pdf. Acesso em: 22 ago. 2007.

LENSSEN, J. P. M. et al. Local adaptation of the clonal plant Ranunculus reptans to flooding along a small-scale gradient. Journal of Ecology, v.92, p.696-706, 2004.
LEVITT, J. Responses of plants to environmental stresses. New York: Academic Press, 1972. 698 p.

LOPEZ, O. R.; KURSAR, T. A. Flood tolerance of four tropical tree species. Tree Physiology. v. 19, p. 925-932, 1999. Disponível em: http:// www.biology.utah.edu. Acesso em: 22 jan. 2008.

MANLY, B. F. J. Multivariate statistical methods: a primer. 2.ed. London: Chapman \& Hall, 1994. 215p.

MARTÍNEZ, G. B. Estudos de espécies florestais e forrageiras de áreas de várzea do Baixo Amazonas-Pará, para uso em sistemas silvipastoris. 2008. $101 \mathrm{f}$. Tese. (Doutorado em Ciências Agrárias) Universidade Federal Rural da Amazônia, Belém, 2008.

MEDRI, M. E. et al. Alterações morfoanatômicas em plantas de Lithraea molleoides (Vell.) Engl. submetidas ao alagamento. Acta Science Biology of Science, v.29, n.1, p.15-22, 2007.

MIELKE, M. S. et al. Leaf gas exchange, chlorophyll fluorescence and growth responses of Genipa americana seedlings to soil flooding. Environmental and Experimental Botany, v. 50, p. 221-231, 2003. Disponível em: www.sciencedirect.com. Acesso em: 17 mar. 2008.

PIRES, J. L. F.; SOPRANO, E.; CASSOL, B. Adaptações morfofisiológicas da soja em solo inundado. Pesquisa Agropecuária Brasileira, v.37, n.1, p.41-50, 2002

POLLOCK, M. M.; NAIMAN, R. J.; HANLEY, T. Plant species richness in riparian wetlands $-\mathrm{a}$ test of the biodiversity theory. Ecology, v.79, n.1, p.94-105, 1998.

POVH, J. A. et al. Respostas morfológicas e anatômicas de plantas jovens de Chorisiaspeciosa A. St.Hil.(Bombacaceae) sob condições de alagamento. Acta Scientiarum Biological Sciences, v.27, n.3, p.195-202, 2005.

ROGGE, G. D. et al. Metabolismo respiratório de raízes de espécies arbóreas tropicais submetidas à inundação. Revista Brasileira de Botânica, v.21, n.2, 1998. Disponível em: http:// www.scielo.br. Acesso em: 22 jan. 2008.

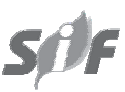


SAS Institute. SAS/STAT. User's guide. Version 6. 4.ed. Cary, 1990. v.2. 846p.

SENA GOMES, A. R.; KOZLOWSKI, T. T. Growth responses and adaptations of fraxinus pennsylvanica Seedlings to flooding. Plant Physiology, v.66, n.2, p.267-271, 1980.

SMIT, B. A.; NEUMAN, D. S.; STACHOWIAK, M. L. Root hypoxia reduces leaf growth: role of factors in the transpiration stream. Plant Physiology, v.92, n.4, p.1021-1028, 1990.

SOARES, J. J.; OLIVEIRA, A. K. M. O paratudal do Pantanal de Miranda, Corumbá-MS, Brasil. Revista Árvore, v.33, n.2, p.339-347, 2009.

STATSOFT INC. STATISTICA. Data analysis software system, version 5.5. 2001. Disponível em: www.statsoft.com. Acesso em: 7 fev. 2007.
TAIZ, L.; ZEIGER, E. Fisiologia vegetal. Porto Alegre: Artmed, 2004. 719p.

VARTAPETIAN, B.B.; JACKSON, M.B. Plant adaptations to anaerobic stress. Annals of Botany, v. 79, p.3-20, 1997. Suplemento A.

VERVUREN, P.J.A.; BOLM, C.W.P.M.; HROON, H. de. Extreme flooding events on the Rhine and the survival and distribution of riparian plant species. Journal of Ecology. n. 19, p. 135-146. 2003. Disponível em: http://www.scielo.br/scielo.php. Acesso em: 25 jan. 2008.

YAMAMOTO, F.; SAKATA, T.; TERAZAWA, K. Physiological, morphological and anatomical responses of Fraxinus mandshurica seedlings to flooding. Tree Physiology, Victoria, v. 15, p.713-719, 1975. 